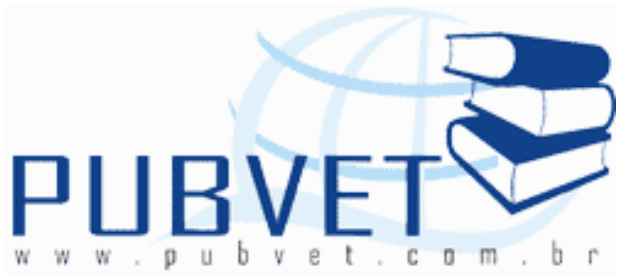

PUBVET, Publicações em Medicina Veterinária e Zootecnia.

\title{
Ocorrência de Schwannoma na vulva de uma vaca
}

Humberto Eustáquio Coelho ${ }^{1}$, Tatiane Furtado de Carvalho ${ }^{2}$, Juliana Marques Fernandes ${ }^{3}$, Karina Barbosa Souza ${ }^{3}$, Hélio Alberto ${ }^{4}$, Claúdio Henrique Gonçalves Barbosa $^{1}$, Rodrigo Supranzetti de Rezende ${ }^{1}$, Flávia Maria Esteves Machado ${ }^{1}$, Aline Oliveira Coelho Magalhães ${ }^{5}$, Cristiano D Amico França Silva ${ }^{6}$, Mateus Guapo Paravina ${ }^{6}$

${ }^{1}$ Professor na Universidade de Uberaba;

${ }^{2}$ Residente de Patologia Animal na Universidade de Uberaba;

${ }^{3}$ Discente do Curso de Medicina Veterinária da Universidade de Uberaba;

${ }^{4}$ Técnico do Laboratório de Anatomia Patológica do Hospital Veterinário de Uberaba (HVU);

${ }^{5}$ Médica Veterinária;

${ }^{6}$ Médico Veterinário da Fazenda Mata Velha.

\section{Resumo}

Foi encaminhada ao Hospital Veterinário de Uberaba, uma amostra para biópsia de uma vaca, nelore, com 48 meses de idade apresentando um aumento de volume na vulva em área despigmentada, com ausência de sangramento. Microscopicamente foi observada a presença de células ovoides e arredondadas com citoplasma grande, núcleos pequenos e bem corados e terminações nervosas, fibras colágenas e fibroblastos. O arranjamento das 
COELHO, H.E. et al. Ocorrência de Schwannoma na vulva de uma vaca. PUBVET, Londrina, V. 5, N. 39, Ed. 186, Art. 1253, 2011.

células neoplásicas se assemelham a rosetas disseminadas pelo tecido conjuntivo. O trabalho tem como objetivo descrever um caso de schwannoma em bovino e discutir os achados anatomoclínicos e enfatizar a importância do diagnóstico histopatológico.

Palavras-chave: Schwannoma, bovinos, histopatológico.

\section{Occurrence of Schwannoma in the vulva of a cow}

\section{Abstract}

Was referred to the Veterinary Hospital of Uberaba, a biopsy sample from a cow, Nelore, with 48 months of age presenting a swelling in the vulva in depigmented area, with no bleeding. Microscopically we observed the presence of rounded and ovoid cells with large cytoplasm, small nuclei and well stained and nerve endings, collagen fibers and fibroblasts. The arrangement of the neoplastic cells resemble rosettes scattered by the tissue. The work aims to describe a case of schwannoma in cattle and discuss the anatomoclinical findings and emphasize the importance of histopathologic diagnosis.

Keywords: Schwannoma, cattle, histopathology.

\section{INTRODUÇÃO}

Dentre os vários tipos celulares, as células de Schwann são as principais constituintes do Sistema Nervoso Periférico (SNP). Elas são confinadas ao SNP e em situações normais raramente são vistas no Sistema Nervoso Central (SNC). As células de Schwann possuem a função de mielinizar ou envolver os axônios do SNP (MIRSKY; JESSEN, 2001). De um ponto de vista prático, as patologias do SNP podem ser divididas em três grandes categorias: neuropatias do SNP, lesões traumáticas e neoplásicas (ORTIZ-HIDALGO; WELLER, 1997).

A célula de Schwann do sistema nervoso periférico é aceita como a origem dos schwannomas, neurofibromas, neurofibrossarcomas. A maioria 
COELHO, H.E. et al. Ocorrência de Schwannoma na vulva de uma vaca. PUBVET, Londrina, V. 5, N. 39, Ed. 186, Art. 1253, 2011.

desses tumores são vistos na pele (JUBB et al., 1993), sendo que dentre esses os mais frequentes são os schwannomas e os neurofibromas (Koestner; Higgins, 2002). Devido as variações das características histológicas da neoplasia e diferenças entre espécies (SUMMERS et al., 1995), há confusões e controvérsias sobre a nomenclatura desses tumores, com relatos conflitando esporadicamente na literatura certificada a origem dessas células (SANTOS, 1971; OSBORN; WEBER, 1983). Neurilemoma, neurinoma, tumor de células de schwann, ou simplesmente, schwannoma são usados por autores que julgam o tumor derivado das células de schwann, tendo origem ectodérmica. Outros autores denominam fibroblastoma ou fibroma perineural, neurofribroma ou sarcoma neurogênico o tumor derivado do endoneuro ou perineuro, admitindo uma origem mesodérmica. Outros autores acreditam que o schwannoma e o neurofibroma são neoplasias distintas (SANTOS, 1971), sendo considerado como schwannomas, os tumores compostos unicamente por células de Schwann ao contrário dos neurofibromas que são considerados os tumores formados por uma grande variedade de tipos celulares incluindo fibroblastos e células perineurais (Hirose et al., 1998).

Os schwannomas acometem caninos, bovinos, felinos (JUBB et al., 1993; WOODRUFF et al., 2000; ZAMECNIK; MICHAL, 2001), equinos, suínos e caprinos, mas são comumente diagnosticados somente em cães e bovinos. Em cães, gatos e bovinos, os tumores benignos presumivelmente originários das células de Schwann são chamados de schwannomas (KOESTNER; HIGGINS, 2002). Segundo Santos (1971) são as neoplasias cranianas, espinhais e dos nervos periféricos mais comuns em medicina veterinária, mais precisamente em bovinos e caninos (JUBB et al., 1993).

Em bovinos, as lesões são múltiplas, compostas por nódulos brancoacinzentados e mais comumente afeta nervos autônomos (SANTOS, 1971; JUBB et al., 1993). Eles são vistos com mais frequência como lesões inesperadas em animais sadios no momento do abate. Nos cães, o diagnóstico de schwannoma tem sido utilizado com mais confiança para os tumores de células fusiformes claramente associadas com troncos nervosos (JUBB et al., 
COELHO, H.E. et al. Ocorrência de Schwannoma na vulva de uma vaca. PUBVET, Londrina, V. 5, N. 39, Ed. 186, Art. 1253, 2011.

1993), acometendo principalmente as raízes nervosas cervical caudal (C6-C8) ou torácica cranial (T1-T2) do plexo braquial, resultando em claudicação, atrofia muscular, dor e suspensão do membro envolvido (sinal de raiz) (NELSON; COUTO, 2010).

Os sinais clínicos dependem da localização do tumor e dos nervos envolvidos. A neoplasia dispõe-se ao longo dos nervos (intercostais, sistema nervoso autônomo simpáticos e ramos do simpático), no plexo braquial (SANTOS, 1971; KOESTNER; HIGGINS, 2002), plexo epicárdico, gânglios simpáticos torácicos e cervicais, plexo nervoso mediastinal e língua (KOESTNER; HIGGINS, 2002). Em bovinos velhos, schawnnomas multicêntricos são muito comuns, mas não causam deficiências neurológicas (SANTOS, 1971; KOESTNER; HIGGINS, 2002). Localizam-se com certa frequência em órgãos e originam-se de nervos simpáticos nestes casos. 0 schwannoma é comumente bem capsulado e pobremente vascularizado. Não é invasor e seu crescimento é lento (SANTOS, 1971).

O diagnóstico frequentemente depende da análise histológica do tumor e da detecção do componente celular que forma a neoplasia e sua relação com as estruturas normais do nervo (ORTIZ-HIDALGO; WELLER, 1997). O uso de técnicas histoquímicas e imunoistoquímicas contribui na determinação da diferenciação e da histogênese do tumor, além de auxiliar no seu diagnóstico e na sua caracterização (KOESTNER; HIGGINS, 2002).

Os schwannomas devem ser diferenciados de outras neoplasias mesenquimais fusiformes incluindo o leiomiossarcoma, sarcoma sinovial, fibrossarcoma, histiocitoma maligno fibroso, sarcoma epitelioide e outros sarcomas de células claras (GRAY et al., 1989). Porém a necessidade de distinguir entre estes tumores e, portanto, a empregar técnicas especiais de investigação, não é justificado por dados prognósticos. Dados pós-operatórios comportamentais sobre estes "tumores de células fusiformes", especificamente diagnosticadas como hemangiopericitoma, fibrossarcoma, schwannoma ou neurofibrossarcoma em critérios histológicos, indicam não haver diferença entre os padrões de crescimento local, a tendência de reincidência, ou a 
COELHO, H.E. et al. Ocorrência de Schwannoma na vulva de uma vaca. PUBVET, Londrina, V. 5, N. 39, Ed. 186, Art. 1253, 2011.

prevalência de metástase de tumores do índice mitótico semelhantes. O grau de anaplasia refletida pelo alto índice mitótico, em vez de identidade do tumor, determina a probabilidade de recidiva ou metástase (JUBB et al., 1993). Entretanto, a distinção entre maligno e benigno é importante porque o prognóstico é bem distinto (CHIJIWA et al., 2004). Quando o tumor é maligno o prognóstico tende a ser desfavorável (PATNAIK et al., 2002).

Histologicamente os schwanomas se manifestam como células fusiformes dispostas entrelaçadas em feixes de várias direções. Podem apresentar diferentes padrões morfológicos (KUWAMURA et al. 1998). Antoni tipo A são repetitivos e dão ao tumor seu carácter uniforme, composto por células fusiformes organizadas como bandas, em zigue-zague, giros, ou paliçadas e Antoni tipo B é degenerativo, mais estromal, menos celular, menos organizado, frouxo e mixoide, às vezes hialinizado. Microcistos podem estar presentes em áreas de mudança mixoide. Tecido cartilaginoso e metaplasia óssea ocorrem com pouca frequência (JUBB et al., 1993). Os corpos de Verocay, formados por numerosos processos celulares tumorais e núcleos arranjados em paliçadas irregulares intercalados com abundante colágeno, são extremamente raros quando comparados com a frequência em que ocorrem nos tumores humanos. As figuras de mitose são raras, o pleomorfismo nuclear e formas bizarras são incomuns (WOODRUFF et al., 2000; KOESTNER; HIGGINS, 2002).

O tratamento é restrito à terapia cirúrgica (LeCOUTEUR, 1996). O grau de anaplasia refletida pelo alto índice mitótico, em vez de identidade do tumor, determina a probabilidade de recidiva ou metástase. Em um grande estudo, os tumores com mais de uma figura de mitose por campo de alta potência, tiveram uma incidência de recorrência de $60 \%$ dentro de três anos, em contraste com apenas $25 \%$ dos tumores de baixo índice mitótico. A maioria das recidivas foram em menos de um ano de excisão inicial. Outro estudo teve uma taxa de recorrência de apenas $21 \%$, e nenhuma associação entre as características histológicas e comportamento posterior como provado. $\mathrm{O}$ intervalo médio entre a excisão inicial de recorrência foi de 21 meses (JUBB et al., 1993). 
COELHO, H.E. et al. Ocorrência de Schwannoma na vulva de uma vaca. PUBVET, Londrina, V. 5, N. 39, Ed. 186, Art. 1253, 2011.

O trabalho tem como objetivo descrever um caso de schwannoma em bovino e discutir os achados anatomoclínicos e enfatizar a importância do diagnóstico histopatológico.

\section{RELATO DE CASO}

Foi encaminhado ao Hospital Veterinário de Uberaba, amostra para biópsia de uma vaca, nelore, com 48 meses de idade apresentando um aumento de volume na vulva em área despigmentada, com ausência de sangramento e ulcerado (Figura 1 ). O proprietário relata que foi realizada a exérese da massa por inúmeras vezes, porém ocorreram recidivas (Figura 2). No último procedimento realizado no animal de exérese do tumor, buscou-se retirar toda a massa visualmente observada com uma grande margem de segurança, procurando evitar a ocorrência de uma nova recidiva, obtendo sucesso (Figura 3). Assim, possibilitou-se a coleta de amostras da vulva e do tumor, que foram fixados em formol para a realização do exame histopatológico.

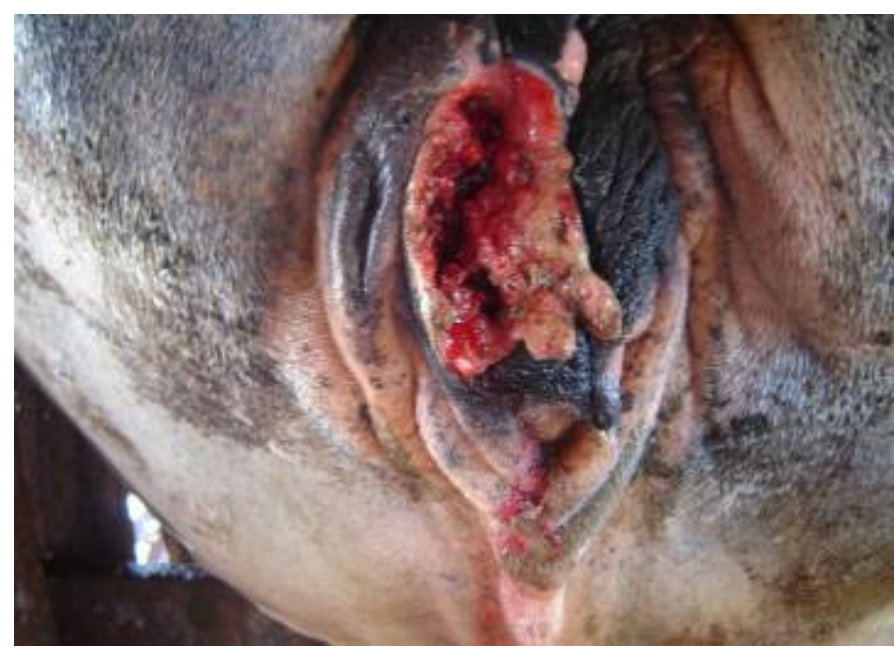

Figura 1. Neoplasia na vulva de uma vaca, com aspecto nodular e ulcerado, observada no dia 09 de dezembro de 2010. 
COELHO, H.E. et al. Ocorrência de Schwannoma na vulva de uma vaca. PUBVET, Londrina, V. 5, N. 39, Ed. 186, Art. 1253, 2011.

No exame histopatológico, observou-se a presença de células ovoides e arredondadas com citoplasma grande, núcleos pequenos e bem corados e terminações nervosas, fibras colágenas e fibroblastos. O arranjamento das células neoplásicas assemelha-se a rosetas disseminadas pelo tecido conjuntivo (Figura 4 e 5). Há presença de células inflamatórias com destaque para os neutrófilos.

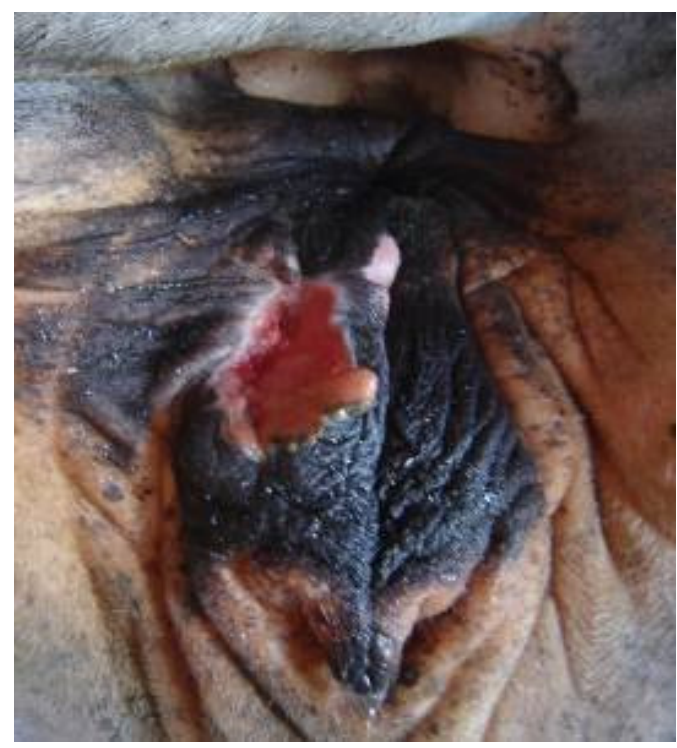

Figura 2. Neoplasia recidivante na vulva de uma vaca, após oito dias da exérese.

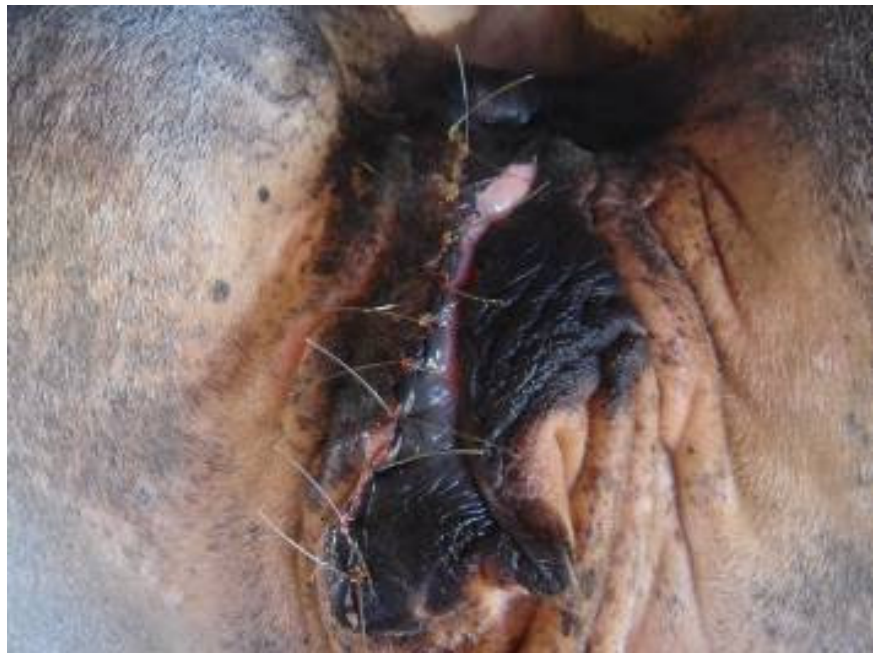

Figura 3. Exérese total da neoplasia realizada no dia 17 de dezembro de 2010. Não houve recidiva. 
COELHO, H.E. et al. Ocorrência de Schwannoma na vulva de uma vaca. PUBVET, Londrina, V. 5, N. 39, Ed. 186, Art. 1253, 2011.

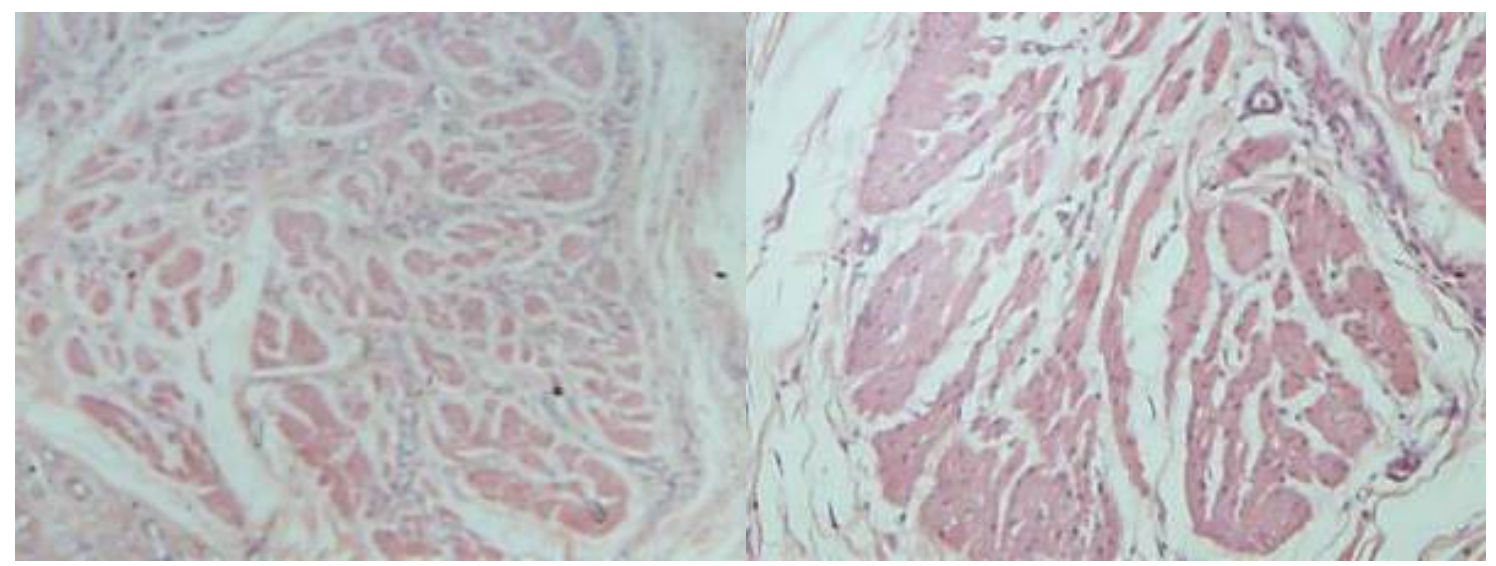

Figura 4. Schwanoma. Presença de células ovoides e arredondadas com citoplasma grande, núcleos pequenos e bem corados. Aumento $4 \mathrm{x}$ e 10x. Coloração HE.

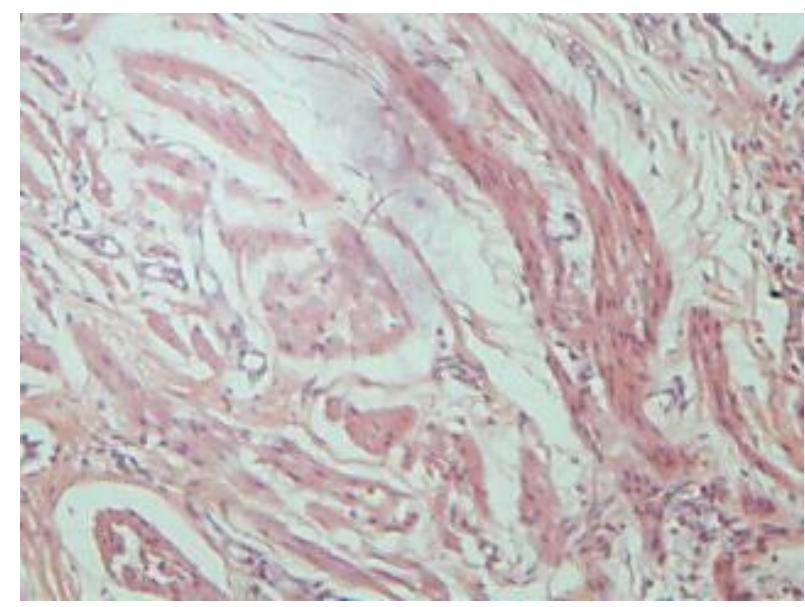

Figura 5. Histologicamente os schwanomas se manifestam como células fusiformes dispostas entrelaçadas em feixes de várias direções. Aumento 10x. Coloração HE. 
COELHO, H.E. et al. Ocorrência de Schwannoma na vulva de uma vaca. PUBVET, Londrina, V. 5, N. 39, Ed. 186, Art. 1253, 2011.

\section{DISCUSSÃO}

O bovino em questão foi acometido pelo schwannoma na região vulvar despigmentada, fato este que contradiz Koestner e Higgins (2002) que relatam que esta neoplasia dispõe-se ao longo dos nervos (intercostais, sistema nervoso autônomo simpáticos e ramos do simpático), no plexo braquial, plexo epicárdico, gânglios simpáticos torácicos e cervicais, plexo nervoso mediastinal e língua. A sua ocorrência concorda com Jubb et al. (1993) que citam que a maioria desses tumores são vistos na pele.

Em bovinos, as lesões são múltiplas, compostas por nódulos brancoacinzentados (SANTOS, 1971; JUBB et al., 1993), que não sangram, pois de acordo com Santos (1971) é pobremente vascularizado, não é invasor e seu crescimento é lento o que favorece sua exérese.

O tratamento de escolha foi a excisão cirúrgica da neoplasia, conforme preconizado por LeCouteur (1996).

O método diagnóstico empregado foi o estudo histopatológico do material obtido pela excisão cirúrgica por meio da detecção do componente celular que constitui o schwannoma e sua relação com as estruturas normais do nervo conforme recomendado por Ortiz-Hidalgo e Weller (1997).

Os achados microscópicos estão de acordo com a descrição de Woodruff et al. (2000) e Koestner e Higgins (2002) que definem os schwannomas como um denso agregado uniforme de células com uma forma ovoide ou fusiforme alongada, bordas citoplasmáticas bem definidas e embebidas em uma matriz densa e variável de colágeno. Os tumores são compostos por um denso padrão celular entrelaçado contínuo ou concêntrico.

Por não apresentar grau de mitose visto histopatologicamente foi possível classificar o tumor como benigno, o que é citado por Jubb et al. (1993) como importante, pois determina a probabilidade de não ocorrer recidiva ou metástase. Ainda Chijiwa et al. (2004) citam a importância da distinção entre maligno e benigno para se caracterizar um prognóstico, que no caso relatado foi favorável. 
COELHO, H.E. et al. Ocorrência de Schwannoma na vulva de uma vaca. PUBVET, Londrina, V. 5, N. 39, Ed. 186, Art. 1253, 2011.

\section{CONCLUSÃO}

Há poucos casos descritos de schwannomas em bovinos, apesar de a literatura relatar que estas neoplasias dentre os animais domésticos são mais comuns em bovinos e cães. A escassez de relatos talvez possa ser atribuída à divergência quanto à distinção das neoplasias dos nervos periféricos em schwannomas e neurofibromas. O relato enfatiza a importância do diagnóstico histopatológico para determinação e diferenciação das neoplasias dos nervos periféricos.

\section{REFERÊNCIAS}

CHIJIWA, K.; UCHIDA, K.; TATEYAMA, S. Immunohistochemical evaluation of canine peripheral nerve sheath tumors and other soft tissue sarcomas. Veterinary Pathology, v. 41, p. 307$318,2004$.

GRAY, M. H.; ROSENBERG, A. E.; DICKERSIN, R.; BHAN, A. K. Glial Fibrillary Acidic Protein and Keratin Expression by Benign and Malignant Nerve Sheath tumors. Human Pathology, v. 20, n. 11, p. 1089-1096, 1989.

HIROSE, T.; SCHEITHAUER, B. W.; SANO, T. Perineurial malignant peripheral nerve sheath tumor (MPNST): A clinicophatologic, immunohistochemical and ultrastructural study of seven cases. The American Journal of Surgical Pathology, v.22, p.1368-1378, 1998.

JUBB, K. V. F.; KENNEDY, P. C.; PALMER, N. Pathology of domestic animals. 4. ed. San Diego: Academic Press, v. 1, p.437 e 723-724, 1993.

KOESTNER, A.; HIGGINS, R. J. Tumors of the nervous system. In: MEUTEN, D.J. (Ed). Tumors of domestic animals. 4.ed. Iowa: Iowa State, p.697-738, 2002.

KUWAMURA M., YAMATE J., KOTANI T., TAKEUCHI T., SAKUMA S. Canine Peripheral Nerve Sheath Tumor with Eosinophilic Cytoplasmic Globules. Veterinary Pathology, v.35, p.223-6, 1998.

LeCOUTEUR, R.A. Tumors of nervous system. In: WITHROW, S. J. Small animal oncology. 2.ed. Philadelphia: Saunders, p.393-419, 1996.

NELSON, R. W.; COUTO, C. G. Medicina interna de pequenos animais. 4.ed. Rio de Janeiro: Elsevier, p.1096-1097, 2010.

MIRSKY, R.; JESSEN, K. R. Embryonic and early postnatal development of Schwann cells. In: JESSEN, K. R.; RICHARDSON, W. D. Glial cell development. 2. ed. Oxford: New York, cap. 1, p. 1-20, 2001.

ORTIZ-HIDALGO, C.; WELLER, R. O. Peripheral Nervous System. In: STERNBERG, S. S. Histology for Pathologists. Philadelphia: Lippincott, cap. 12, p. 285-311, 1997. 
OSBORN, M; WEBER, K. Tumor diagnosis by intermediale filament typing: A novel tool for surgical pathology. Laboratory Investigation, v. 48, p. 374-394, 1983.

PATNAIK, A. K.; ZACHOS, T. A.; SAMS, A. E. Malignant nerve-sheath tumor with divergent and glandular differentiation in a dog: A case report. Veterinary Pathology, v.39, p.406-410, 2002.

SANTOS, J. A. Patologia especial dos animais domésticos (mamíferos e aves). 1.ed. Rio de Janeiro: Brasil. OEA, 1971.

SUMMERS, B. A.; CUMMINGS, J. F.; LAHUNTA, A. Neoplasia and the peripheral nervous system. In: Veterinary neuropathology. St. Louis, p.472-481, 1995.

WOODRUFF, J. M.; KOUREA, H. P.; LOIS, D. N. Tumors of cranial and peripheral nerves. In: KLEIHUES, P.; CAVENEE, W. K. (Eds). Pathology and genetics of tumors of the nervous system. Lyon: IARC, p.164-174, 2000.

ZAMECNIK, M.; MICHAL, M. Perineurial cell differentiation in neurofibromas. report of eight cases including a case with composite perineuroma-neurofibroma features. Pathology, Research \& Practice, v.197, p.537-544, 2001. 